\title{
Characteristics of cosmetic medical tourism in Korea
}

\author{
Chang-Won Koh, MD, PhD \\ Department of Gynecologic Oncology, Sheik Khalifa Specialty Hospital, Ras Al Khaimah, United Arab Emirates
}

This review explores strategies to promote medical tourism in Korea through assessing the characteristics of cosmetic medical tourism selection by nationality, visiting clinics, and consumption tendency. It also discusses several issues regarding the medical tourism market in Korea, such as patient safety, patient satisfaction, medical visas, tax refunds, and legal aspects. The author reviewed articles that involved the cosmetic medical tourism in korea and summarized their findings. In 2015, the number of foreign pathients was 296,889 , registering an increase of $11.1 \%$ compared to that of the previous year. This increasing trend has been registered since 2009, with an overall increase of $30.5 \%$ between 2009 and 2015. The number of registered medical institutions was 3,013 and that of medical tourism agencies 1,666 in 2016. In 2015, cosmetic surgery reported the highest total amount of medical costs from foreign patients, followed by internal medicine, general surgery, and medical checkups in this order. The government of South Korea supports medical tourism policies through programs that include the accreditation of medical institutions, issuance of medical visas, tax refunds, and assistance for medical dispute resolution. Recently, in an effort to support medical tourism through a systematic approach, the institution of MEDICAL KOREA was established in 2016. Various measures taken by the government are expected to help activate and promote medical tourism by ensuring quality medical services to be provided to medical tourists.

Keywords: medical tourism; medical tour; Korea; cosmetic; MEDICAL KOREA

\section{Introduction}

The healthcare system in Korea is open to foreigners, who are offered the same treatment as locals in terms of quality and safety at reasonable costs. Medical services are provided not only as medical treatment for illnesses, but also for cosmetic purposes. If side effects occur during this course of treatment, there is support for medical dispute mediation and resolution.

Recently, the number of foreigners visiting Korea to receive medical services has been increasing annually. Specifically, the number of foreign patients who received medical services in Korea increased from 60,000 in 2009 to 296,889 in 2015 [1]. As the demand for medical tourism has been increasing annually, in 2015, the Ministry of Health and Welfare Act enacted the Act on Overseas Medical Expansion and Foreign Patient Attraction Support to support medical tourism. The Enforcement Decree of the law mandates the designation of medical institutions to attract foreign patients, suppression of illegal brokers along with a reporting and reward system, investigation into medical costs and fees, and the application of the malpractice liability insurance by medical institutions that receive foreign patients. The MEDICAL KOREA support center, which acts as a comprehensive support center for foreign patients, was established in 2016, making it possible to provide comprehensive support for foreign patients. Specifically, the organization provides support through activities such as overseeing foreign patient agencies and medical institutions, issuance of medical visas, tax refunds, and medical dispute mediation [2]. 
To stimulate the further growth of medical tourism in Korea, quality medical services should be provided to foreign patients to induce confidence in the reliability of the services offered. Additionally, it is necessary to increase healthcare accessibility and convenience for foreigners who seek to receive these quality services in Korea. These measures will contribute to increasing patient satisfaction and, consequently, the proportion of individuals who recommend medical tourism would also rise. The purpose of this review is to explore the strategies behind promote medical tourism in Korea by reviewing the characteristics of cosmetic medical tourism selection by nationality, visiting clinics, and consumption tendency.

\section{Current status of medical tourism in Korea}

In this study, medical tourism is defined as the travel of patients from their residence country to other places in the world for the purpose of receiving medical services in this study [3]. The number of patients who visit Korea for medical tourism is increasing yearly. In 2010, the total number of medical tourists to Korea was 81,000 , having increased to 297,000 by 2015 . Moreover, the number of admitted patients was 7,987 in 2010, having increased to 24,489 by 2015 . Outpatients also increased from 63,819 in 2010 to 247,330 in 2015 , as did those who visited South Korea for medical checkups from 9,911 in 2010 to 25,070 in 2015. Medical treatment revenues increased accordingly from KRW 103.2 billion in 2010 to KRW 669.4 billion in 2015 (Table 1) $[2,4]$.

Hospital expenditure by medical specialty is highest in plastic surgery with KRW 185.6 billion, followed by internal medicine with KRW 105.3 billion and general surgery with KRW 48.6 billion. The average medical cost per person was KRW 2.25 million, and the number of patients who spent KRW 100 million or more increased by $29.0 \%$ (i.e., from 201 to 271 ) between 2014 and 2015. According to the nationality of foreign patients, the medical costs of those from China were the highest at KRW 21.71 billion, followed by Russia at 79.2 billion, the United States at 74.5 billion, and Kazakhstan at 58 billion. Regarding medical costs per person, the top country was the United Arab Emirates with KRW 15.03 million, followed by Kazakhstan with 4.61 million and Russia with 3.8 million in 2015 (Table 2) [4].

In 2015, 165,689 foreign patients received medical treatment in Seoul. Regarding the regions where foreign patients receive medical services, most foreign patients received treatment in Seoul, followed by Gyeonggi Province, Incheon Metropolitan City, Busan Metropolitan City, and Daegu Metropolitan City in descending order. In 2015, the number of medical institutions that attracted 100 or more foreign patients was 325 , and that of the medical institutions that attracted 1,000 or more was 83 [1].

\section{Cosmetic medical tours}

Among the 296,889 patients who visited South Korea in 2015

Table 2. Income, distribution, per person cost by departments in 2015

\begin{tabular}{lccc}
\hline & $\begin{array}{c}\text { Income } \\
\text { (100 million } \\
\text { Korean Won) }\end{array}$ & $\begin{array}{c}\text { Distribution } \\
\mathbf{( \% )}\end{array}$ & $\begin{array}{c}\text { Per person cost } \\
\text { (10 thousand } \\
\text { Korean Won) }\end{array}$ \\
\hline Plastic surgery & 1,856 & 27.7 & 450 \\
\hline $\begin{array}{l}\text { Internal } \\
\text { medicine }\end{array}$ & 1,053 & 15.7 & 133 \\
\hline $\begin{array}{l}\text { General surgery } \\
\text { Medical } \\
\text { examination }\end{array}$ & 486 & 7.3 & 362 \\
\hline $\begin{array}{l}\text { Obstetrics \& } \\
\text { gynecology }\end{array}$ & 341 & 6.7 & 132 \\
\hline Dermatology & 324 & 5.1 & 179 \\
\hline Orthopedics & 324 & 4.8 & 101 \\
\hline Neurosurgery & 279 & 4.2 & 144 \\
\hline Ear, nose, throat & 179 & 2.7 & 159 \\
\hline Dental clinic & 160 & 2.4 & 142 \\
\hline Urology & 135 & 2.0 & 150 \\
\hline Ophthalmology & 101 & 1.5 & 90 \\
\hline Traditional \\
medicine
\end{tabular}

Table 1. Medical tour patient number in Korea

\begin{tabular}{lrrrrrrr}
\hline \multicolumn{1}{c}{ Year } & $\mathbf{2 0 1 0}$ & $\mathbf{2 0 1 1}$ & $\mathbf{2 0 1 2}$ & $\mathbf{2 0 1 3}$ & $\mathbf{2 0 1 4}$ & $\mathbf{2 0 1 5}$ \\
\hline Patients & $\mathbf{2 1 , 7 8 9}$ & 122,297 & 159,464 & 211,218 & 266,501 & 296,889 \\
Admission & 7,987 & 11,945 & 14,809 & 20,137 & 23,855 & 24,489 \\
Out patient & 63,819 & 95,810 & 128,711 & 172,702 & 221,672 & 247,330 \\
Medical examination & 9,911 & 14,542 & 15,944 & 18,379 & 20,974 & 25,070 \\
Income & 1,032 & 1,809 & 2,673 & 3,934 & 5,569 & 6,694 \\
\hline
\end{tabular}


for medical tourism, those visiting a plastic surgeon's office amounted to 41,263 . The number of plastic surgery patients was $13.9 \%$ of the total number of medical tourism patients in 2015 , registering an increase by more than $10 \%$ compared to the previous year. Comparatively, the number of patients who saw a dermatologist for medical treatment was 31,900 (Table 3) [4].

The total costs of cosmetic surgery reached KRW 185.6 billion, being the highest figure of all expenses by medical specialty, while the medical costs for dermatology were KRW 32.4 billion. The medical cost per patient was the highest in plastic surgery with KRW 4.5 million, and KRW 1.01 million in dermatology (Table 2). The Chinese comprised the highest proportion of cosmetic surgery patients, with 26,537 Chinese using the medical services of cosmetic surgery. The number of Chinese patients who received dermatology medical treatment was 13,692, and that of Japanese 2,809. The number of the individuals accompanying a patient who visited Korea for cosmetic treatment averaged 1.25 [1]. In 2016, the MEDICAL KOREA proposed a list of medical costs for cosmetic surgery to be applied to foreign patients as a market consolidation measure. It also provided descriptions of the medical costs of frequent surgeries and treatments, and specified recovery time. Based on the division of eight body parts, treatments were classified into 45 detailed procedures $[2,4]$.

Since medical tourism means receiving medical treatment abroad, several requirements must be met to satisfy patients. In 2015, a survey reporting about foreign patient satisfaction showed that the overall degree of satisfaction of patients was found to be $88.8 \%$ for 677 individuals who received outpatient services for cosmetic purposes. Regarding patient satisfaction, the satisfaction of Japanese patients was the lowest at $84.2 \%$ and that of patients from Hong Kong was the highest at 93.9\%. Chinese patients, who comprise the largest proportion of foreign cosmetic patients, showed a medium-level satisfaction of $88.5 \%$ [1].

As more foreign patients receive treatment in Korea, the complaints about treatment side effects and dissatisfaction with medical services increased as well. In the Medical Dispute Mediation and Arbitration Agency, the cases of consultation for the patients who received plastic surgery treatment also increased from 5 in 2012 to 24 in 2015. Initially, visit consultations were the most frequent, but the most common type of consultation in 2015 was by telephone (15 cases). For arbitration and mediation concerning foreign plastic surgery patients, one case was received in 2012 and 10 in 2015. Among those cases, investigation was initiated for four cases, while the other six cases were dismissed. The average claim for malpractice was KRW 6 million in 2012, compared to KRW 34 million in 2015 [5].

\section{Support policies in 2016}

To encourage medical tourism, the government has implemented measures such as value added tax (VAT) refunds; the establishment of MEDICAL KOREA; support for projects to attract foreign patients, for the certification of medical institutions, and for the issuance of medical visas. The VAT refund system has been implemented since 2016 to reduce medical costs for foreign patients. MEDICAL KOREA, an organization established by the government, provides information on the expenses of frequent medical treatments for foreigners, and also offers guidance and reporting on illegal information brokers and provides support for patients coping with medical disputes in association with relevant organizations. To operate a business to attract foreign patients, it is necessary to register a business institution for this purpose in accordance with the medical law. As of September 2016, there were 3013 currently registered medical institutions and 1,666 agencies to attract foreign patients. Additionally, efforts are being made to increase the accreditation of medical institutions towards quality healthcare and patient safety. For instance, 29 institutions received the Joint Commission International (JCI) accreditation in 2015. The certification of medical institutions can increase patient satisfaction. Furthermore, if an extension of treatment duration is required for foreign patients, support is provided so that they can change their visas from C-3-3 (Short-term Medical Tourist Visa) to G-1-10 (Recuperation \& Treatment Visa) [2].

\section{Discussion}

Medical tourism represents a combination of healthcare and tourism [3]. However, from a narrow definition, it means travel only the treatment of diseases, such as receiving surgery abroad

Table 3. The number of the patient at cosmetic surgery and dermatology

\begin{tabular}{lcccccccc}
\hline \multicolumn{1}{c}{ Year } & $\mathbf{2 0 0 9}$ & $\mathbf{2 0 1 0}$ & $\mathbf{2 0 1 1}$ & $\mathbf{2 0 1 2}$ & $\mathbf{2 0 1 3}$ & $\mathbf{2 0 1 4}$ & $\mathbf{2 0 1 5}$ \\
\hline Cosmetic surgery & 2,851 & 4,708 & 10,387 & 15,898 & 24,075 & 36,224 & 41,263 \\
Dermatology & 6,015 & 9,579 & 12,978 & 17,224 & 25,101 & 29,945 & 31,900 \\
\hline
\end{tabular}


$[6,7]$. The government of the republic of Korea is carrying out the infrastructure expansion and institutional maintenance related to medical tourism, thus making efforts to foster the medical tourism industry, which is seen as the convergence of tourism and medical industries [8]. Medical tourism is a high valueadded service market formed by a combination of industries, of different types, and is expected to show sustainable growth in the future [3].

In medical tourism, patient satisfaction is determined by the background of the patient, surgical procedures, quality of the doctor, and quality of the medical facilities $[9,10]$. Generally, patients receiving cosmetic treatment experience anxiety and emotional instability until recovery. If a satisfactory clinical result is reached, patient satisfaction is generally high [11]. If foreign patients can easily obtain information on the necessary healthcare services using the Internet or by other means without visiting Korea, they will be able to decide whether to visit Korea, as a result of obtaining more detailed description of the treatment to receive and the costs, which they can easily compare them with the costs of other countries. If a medical institution has received the international certification, and if the quality of medical personnel is also guaranteed by the government, reliability increases. MEDICAL KOREA is providing assistance, so that the patient will be introduced to a reliable medical tourism agency and receive treatment after deciding to visit Korea to receive treatment. The organization is also making various efforts to ensure that the patients can easily visit Korea and get good medical services. Moreover, it is providing comprehensive services, including support for JCI accreditation for securing the international credibility of medical institutions; support for entry and departure procedures of medical tourists and guardians; provision of guidance on medical tourism hospitals for foreigners; and translation assistance, counseling support and call center operation, accommodation booking, guidance on the insurance business and support for insurance application and claim processes, support for the issuance of various documents, and support for the treatment after patients return to their home countries.

With respect to unexpected costs caused by receiving medical treatment in a foreign country, a method for offering reasonable compensation should be presented [12]. To address these concerns, medical dispute resolution must be encouraged. The results of the surveys on foreign patient satisfaction conducted by the Korea Health Industry Development Institute over five years since 2011 showed that a shortage of detailed descriptions about medical services and a lack of specific explanations on medical costs were cited as the major unmet needs with respect to the inadequate aspects of the medical services. Moreover, non-medical services, such as food provision to suit various tastes, were considered important. To improve these problems, it is necessary to provide foreign patients a detailed description on treatment time; waiting time for hospitalization, surgery, and medical tests; diseases and conditions; and the results after treatment. Additionally, continuous improvement of non-medical services, such as menus and variety of menus, is required.

The Ministry of Culture, Sports and Tourism and the Korea Tourism Organization are responsible for the statistics related to healthcare and tourism, on which the Korea Health Industry Development Institute conducts surveys. It is necessary to conduct a comprehensive analysis of the statistical data collected by MEDICAL KOREA, and utilize it as the basic data for creating a healthcare ecosystem that can increase the number of medical tourists who visit Korea and receive medical services. With respect to the creation of the healthcare ecosystem, there is also a need to improve proficiency in multiple foreign languages to resolve the language problems related to medical tourism [8].

\section{Conclusion}

Healthcare consumers travel to Korea to receive medical services. This review discusses several issues of the medical tourism market in Korea, such as patient safety, patient satisfaction, medical visas, tax refunds, and legal aspects. Several measures are expected to help trigger and promote medical tourism by ensuring that quality medical services are provided to the medical tourists in Korea. In conclusion, it is considered critical for the activation of medical tourism to open the healthcare system to foreigners, implement a medical tourism system, and develop methods for increasing the satisfaction of foreign patients.

\section{Conflicts of interest}

The author has nothing to disclose.

\section{References}

1. Korea Health Industry Development Institutions. Foreign patients satisfaction research report. Sejong: Korea Health Industry Development Institutions; 2015.

2. Medical Korea. Medical Korea [Internet]. Osong: Medical Korea; updated 2015 Mar 9, cited 2016 Dec 9. Available from: http://www.medicalkorea.or.kr. 
3. Kwak DY. Improvement plan of readiness for inbound medical tourists. J Tour Enhanc 2014;2:21-34.

4. Korea Health Industry Development Institutions. Statistics on international patients in Korea, 2015. Sejong: Korea Health Industry Development Institute; 2015.

5. Korea Medical Dispute Mediation and Arbitration Agency. Medical dispute mediation and arbitration statistical yearbook. Seoul: Korea Medical Dispute Mediation and Arbitration Agency; 2015.

6. Smith R, Martínez Álvarez M, Chanda R. Medical tourism: a review of the literature and analysis of a role for bi-lateral trade. Health Policy 2011;103:276-82.

7. Seo SY, Lee JW, Lee HY. The effect of risks and benefits perceived in the global healthcare tourism on choice for destination country. Korean J Tour Res 2015;30:143-63.
8. Han JY, Choi EM, Ji KY. An analysis of the importance-satisfaction of convergent medical tourism service quality. J Digit Converg 2015;13:403-12.

9. Lunt N, Carrera P. Medical tourism: assessing the evidence on treatment abroad. Maturitas 2010;66:27-32.

10. Song MK, Kim SH. A study on the differences of medical tourism selection attributes by nationality, visiting Purpose, and consumption tendency-focused on Chinese and Japanese medical tourists. Korean J Tour Res 2015;30:331-51.

11. Kim YA, Chung HY. Factors affecting plastic surgery addiction tendency among undergraduate women. J Digit Converg 2014;12:621-31.

12. Miyagi K, Auberson D, Patel AJ, Malata CM. The unwritten price of cosmetic tourism: an observational study and cost analysis. J Plast Reconstr Aesthet Surg 2012;65:22-8. 